\title{
Price Determination in Public Procurement: A Game Theory Approach
}

\author{
Martin Schmidt
}

\begin{abstract}
:
The article examines mechanism of bid price determination in public procurement by individual tenderers. A game theory approach is used to analyse this process. Firstly, a simple model with two firms illustrates the influence of expected opponent's decision in bid price setting. Assumptions are released subsequently and a game theory based model describes price determination under assumption of expected profit maximization. It is shown that the bid price depends on the costs associated with the performance of the contract and the expected number of bidders. The relationship between the amount of the bid price and the number of bids is also confirmed on the findings of several empirical studies that are quoted.
\end{abstract}

Key words: Public procurement; Award procedure; Bid price; Game theory.

JEL classification: H57

\section{Introduction}

Public procurement is a highly formal process, which is regulated in the Public Procurement Act $^{1}$. The law strictly determines the procedures of contracting entities and limits their decision possibilities. The objective of the awarding process is the conclusion of a contract with the "best" supplier who meets all the requirements and offers the performance at the lowest cost. When most economically advantageous tender is used as an award criterion, it is aimed to conclude a contract with a supplier whose tender achieved the best ratings on the basis of criteria relating to the price or utility value.

Throughout the procurement process, starting with the creation of procurement documentation to the actual performance of the contract, conflicts of interests of various entities arises. This typically involves a contracting authority and individual suppliers willing to win the contract. It is reasonable to assume that both contracting authority and suppliers (tenderers) do not decide completely isolated regardless of other subjects, but that they take the expected reaction of the counterparty into account. A contracting authority, for instance, calculates on possible reaction of a tenderer that has made some mistake in his tender and decides whether to exclude the tenderer or allow him to correct the mistake. In this case, it can be assumed that the excluded tenderer will probably defend himself through submitting objections and proposal to the Office for the Protection of Competition (ÚOHS). Such a situation may for the contracting authority entail

Ing. Martin Schmidt - Faculty of Economics and Administration, Masaryk University; $<$ m.schmidt@email.cz>.

1 Act No. 137/2006 Coll. 
additional costs associated with the procurement procedure and delay of a few months (in extreme cases even years). A rationally acting contracting authority will therefore include the possible reaction of counterparty in the mentioned decision problem. Another example of decision-making situation in which the outcome simultaneously depends on decision of another subject (opponent) is a determination of tender price.

The goal of this article is an analysis of the decision-making situation on the supply side in public procurement, i.e. the process of price determination executed by firms bidding for a public contract. This process is analysed using the game theory approach.

This paper uses simple game theory models as well as findings of the literature about prices in public procurement. Basic principles of game theory are firstly illustrated by the matrix model with two firms. Assumptions are released subsequently and a model based on auction theory describes price determination under assumption of expected profit maximization. Findings of the model are then confronted with several empirical studies about prices in public procurement.

Game theory is a branch of economic theory, which focuses on analysing and modelling conflict decision situations, which involve more subjects (players). Individual players select from possible alternatives (set of strategies) while considering choices of opponent. The output of the game is determined for each combination of strategies of players by so-called payoff function or payoff matrix (Dlouhý, Fiala, 2009, pp. 7-9). Actual payout of the game typically depends on the decisions of both players but none of them has the result entirely under control.

The optimal strategy of one player is affected by the optimal strategy of opponent. In the model players typically have perfect information about other players, i.e. they know the sets of strategies and values of payoff function. The optimal strategy achieves Nash equilibrium, which is a solution when no player has anything to gain by changing only his own strategy (Osborne, 2004, pp. 21-24). Therefore, if a player deviates from the optimal strategy, his outcome will decline. Optimal (equilibrium) strategy can be a specific strategy of each player then we are talking about the Nash equilibrium in pure strategies, or it may be a probability of choice of several strategies, then it is the Nash equilibrium in mixed strategies (Osborne, 2004, pp. 99-108).

The game theory is one of the most mathematical parts of economics while it uses in its model quantitative methods such as matrix calculations, various equations and optimization and statistical methods. In terms of application in public procurement, game theory can be used for describing and explaining of behaviour of tenderers, especially decisions about the bid price when considering competitors. Especially parts of game theory related to theory of auctions appear to be relevant. 
Although game theory builds on earlier work, its origin is associated with the book by John von Neumann and Oskar Morgenstern "Theory of Games and Economic Behaviour" from 1944 (Osborne, 2004, pp. 2-3). Game theory is also applied in several economic articles to the field of public procurement.

The theory of auctions, which is a part or the game theory, is used in order to theoretically explain the influence of number of tenders on the bid price by for instance Gilley, Karels (1981), Gómez-Lobo, Szymanski (2001), Iimi (2006), Eustache, Iimi (2008) or Onur, Ozcan, Tas (2012). Porter and Zona (1993) test occurrence of bid rigging with an auction model, similarly Bajari (2001). De Silva, Kosmopoulou and Lamarche (2008) apply a model based on auction theory to analyse the impact of information on companies entering the public procurement market, as well as Li and Zheng (2009). These authors in their articles mainly focus on the prices and the effects of competition in public procurement. The publications agree on the conclusion that a sufficient competitive environment is essential in public procurement and that a greater number of bidders means a decline of price.

Prisoner's dilemma game is used to analyse the cooperation in works contracts within the dissertation (Ericsson, 2007). Game theory approach is also applied in the article about PPP project (Ho, 2007), which examines the impact of compensations for unsuccessful tenderers and the impact of additional negotiations on the price of the project. The game theory is not only used to explain relations on the supply side, but players from the public sector may also be included, such as in Medda (2007) or Glumaca, Hana, Schaefera and Krabben (2015), who explain negotiation in PPP projects using game theory approach.

\section{Model}

Using game theory it is possible to analyse the decision-making process of firms seeking a public contract and deciding about their bid price. It is obvious that if the firm offers a low price, it will increase the probability of being selected. Such a firm, on the other hand, reaches only a small profit or even a loss. Deciding on the price is thus affected by expectations of prices set by other companies.

\subsection{Simple model}

Firstly, assume two companies (tenderers) deciding about their bid price. For simplicity and greater clarity we limit their options to two - (1) a low bid price at which the company, if selected, achieves the profit of unit $\operatorname{size}^{2},(2)$ a high bid price at which achieves a profit $\lambda$, which is higher than one in the previous case $(\lambda>1)$. The companies mutually decide about the price considering the value of their expected profit:

2 Payoff matrix can be modified to strategically equivalent, e.g. by dividing all elements by a positive value (Osborne, 2004, pp. 149-150). 


$$
\Pi_{e}=(B-C) \cdot p,
$$

Where $\Pi_{e}$ is expected profit, $B$ means bid price, $C$ expresses costs associated with performance of the contract, and $p$ is used for probability of winning the contract.

Values of $\Pi_{e}$ for combinations of possible prices of both firms ${ }^{3}$ are listed in the table (payoff matrix) below. In case that both firms competing for the contract choose the same level of price, the probability $p$ of obtaining the contract equals 0,5 for each of these companies. Within the model, we focus on analysing the conflicting decision situation, therefore we abstract from the possible influence of different cost structure between the firms.

\section{Tab. 1: General payoff matrix for two firms}

\begin{tabular}{cccc}
\hline & & low price & firm 2 \\
\hline 节 & low price & $p ;(1-p)$ & $1 ; 0$ \\
& high price & $0 ; 1$ & $p \cdot \lambda ;(1-\mathrm{p}) \cdot \lambda$ \\
\hline
\end{tabular}

Source: Authorial computation.

Equilibrium strategy of the game depends on the size of the profit gained by the firm with the high bid price (if selected), i.e. on the value of the parameter $\lambda$. In case of two firm $(p=0,5)$ and for $1<\lambda<2$ the choice of low bid price is the dominant strategy of these firms. Upper limit of $\lambda$ may be assumed, for instance, because of the maximal price that is accepted by contracting authority and therefore it is possible to achieve only certain level of profit. This case is described by the game of prisoner's dilemma as illustrated in the payoff matrix for $\lambda=1,5$.

\section{Tab. 2: Payoff matrix - prisoner's dilemma}

\begin{tabular}{|c|c|c|c|}
\hline & \multicolumn{2}{|c|}{ firm 2} \\
\hline & & low price & high price \\
\hline \multirow{2}{*}{$\overrightarrow{\mathrm{I}}$} & low price & 0,$5 ; 0,5$ & $1 ; 0$ \\
\hline & high price & $0 ; 1$ & 0,$75 ; 0,75$ \\
\hline
\end{tabular}

Source: Authorial computation.

Prisoner's Dilemma is probably the most famous game in the context of game theory characterized by the equilibrium strategy that is not Pareto optimal ${ }^{4}$. In this case it is always for both firms preferable to select the low bid price regardless of

3 Company 2 can also be seen as a simplified aggregation of other companies then the probability $p$ is equal to $1 / n$, where $n$ is the number of firms applying for a public contract.

4 Pareto optimum is such a state when it is impossible to improve the situation of any individual without worsening situation of another individual. 
European Financial and Accounting Journal, 2015, vol. 10, no. 1, pp. 49-62.

the opponent's strategy. Equilibrium is thus a "low-low" strategy, which has, however, for both players lower values of payoff matrix than "high-high" strategy. This optimal strategy refers to the game played ones. A cooperative strategy with high prices may be possible in case of repeated games; while in practice it may be a form of prohibited agreements, so-called bid rigging.

The payoff matrix has following form for values of the parameter $\lambda>2$. Three Nash equilibria exist for this level of profit; two of them are in pure and one in mixed strategies. In this case, the situation is described by a stag hunt game.

Tab. 3: Payoff matrix - stag hunt

\begin{tabular}{|c|c|c|c|}
\hline & \multicolumn{2}{|c|}{ firm 2} \\
\hline & & low $(b=1)$ & $\operatorname{high}(b=0)$ \\
\hline \multirow{2}{*}{$\bar{E}$} & $\begin{array}{c}\text { low } \\
(a=1)\end{array}$ & 0,$5 ; 0,5$ & $1 ; 0$ \\
\hline & $\begin{array}{l}\text { high } \\
(a=0)\end{array}$ & $0 ; 1$ & $0,5 \lambda ; 0,5 \lambda$ \\
\hline
\end{tabular}

Source: Authorial computation.

Following reaction curves can be derived for values of the parameter $\lambda>2$. Parameter $a$ indicates the probability of choice strategy "low" by firm 1 and parameter $b$ indicates the probability of choice strategy "low" by firm 2 . Values ( 1 $-a)$ and $(1-b)$ thus express probability of selecting strategy "high" by a relevant firm.

\section{Fig. 1: Reaction curves}

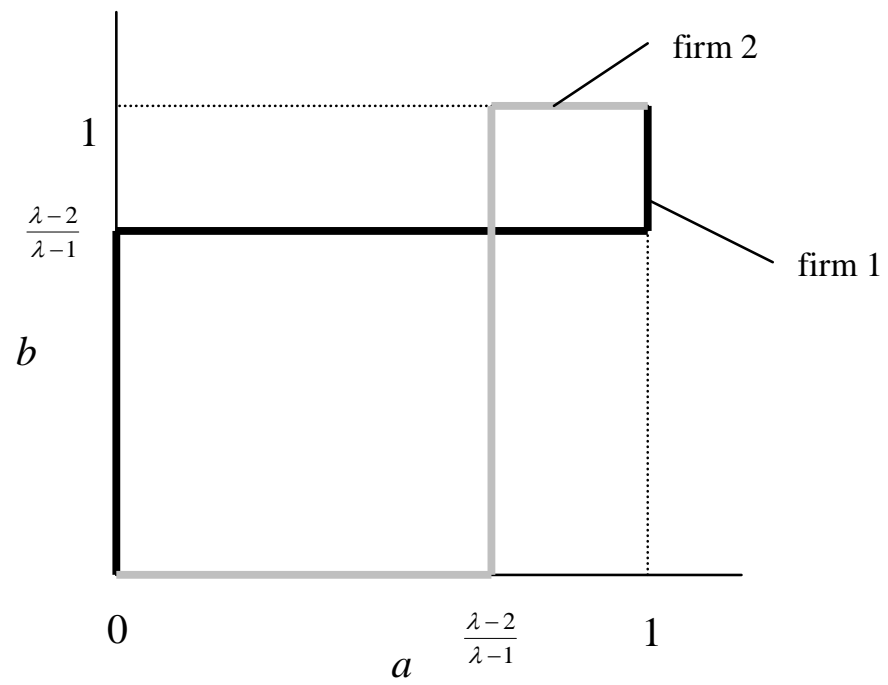


firm 1: $a=\left\{\begin{array}{l}\left.0 \quad \ldots b \in<0 ; \frac{\lambda-2}{\lambda-1}\right) \\ <0 ; 1>\ldots b=\frac{\lambda-2}{\lambda-1} \\ 1 \quad . . b \in\left(\frac{\lambda-2}{\lambda-1} ; 1>\right.\end{array} \quad ;\right.$ firm $2: b=\left\{\begin{array}{l}\left.0 . . a \in<0 ; \frac{\lambda-2}{\lambda-1}\right) \\ <0 ; 1>\ldots a=\frac{\lambda-2}{\lambda-1} \\ 1 \quad \ldots a \in\left(\frac{\lambda-2}{\lambda-1} ; 1>\right.\end{array}\right.$

Source: Authorial computation.

Three equilibrium strategies can be shown in Figure 1 at the intersection of reaction curves - "low-low" in coordinates $[1 ; 1]$ where the value of payoff function of both companies is equal 0,5 (see payoff matrix); strategy "high-high" in $[0 ; 0]$ with payoff of $0,5 \cdot \lambda$; and the mixed strategy with the value of payoff function 0,5 (expected value calculated from payoff matrix). Because the parameter holds $\lambda>2$, strategy with high prices achieves for both players the highest values of payoff function, this strategy is therefore (dominating) equilibrium strategy.

The mechanism how companies may be deciding about their bid price while considering decisions of other firms was illustrated through the simple game theory model. This decision is influenced by the probability that the firm obtains the contract at certain level of price, i.e. by the number of tenderers. In this simplified model, in which possible prices were limited only to two options, the equilibrium strategy was derived from the ratio of the size of profits made with the high and low bid price (i.e. from the parameter $\lambda$ ). When the expected gain associated with the higher level of price is sufficiently high, the model determines offering the high price as the equilibrium strategy.

\subsection{Model with multiple firms}

Since the model presented above is based on restrictive assumptions, which do not reflect reality much, these restrictions on bid prices and number of firms are loosen in the following text. A subject of interest is mainly determination of specific amount of bid price based on variables such as costs related to the contract or estimated number of companies competing for the contract.

It is assumed in accordance with the economic theory that each company sets the bid price in order to maximize its expected profit $\Pi_{e}$ related to the performing of the contract. The expected profit consists of the difference of income (i.e. the bid price $B$ ) and costs $C$. The amount of the expected profit is also influenced by the probability $p$ that the tender contains the lowest price the tenderer thus wins the contract. The relations presented below are from view of firm no. 1, however in case of $n$ other firm the situation is analogous (symmetric). 


$$
\Pi_{e}=\left(B_{1}-C_{1}\right) \cdot p\left(B_{1}<B_{2} \wedge \ldots \wedge B_{1}<B_{n}\right)
$$

Assume that that the costs related to the performance of the public contract are various among the companies. These costs are randomly distributed; they are thus random samples from a probability distribution, e.g. uniform or normal distribution (with known mean $\mu_{c}$ and variance $\sigma_{c}^{2}$ ). Further assume that individual firms are able to determine or estimate the probability distribution of bid prices based on previous contracts.

The equation (2) for the estimated profit can be adjusted to a form containing the distribution function $F\left(B_{1}\right)$, which is related to the probability distribution of bid prices.

$$
\Pi_{e}=\left(B_{1}-C_{1}\right) \cdot p\left(B_{1}<B_{2}\right) \cdot \ldots \cdot p\left(B_{1}<B_{n}\right)=\left(B_{1}-C_{1}\right) \cdot\left[1-F\left(B_{1}\right)\right]^{n-1}
$$

The value of the expected profit of the company depends on the bid price. At a very low bid price, the company does not cover the costs related to the performance of public contract and does not reach a profit. At a very high value of the bid price, the probability of winning the contract is extremely low on the other hand. These effects work in opposite directions; however the expected profit is maximized at a certain value of the bid price (see figure 2).

\section{Fig. 2: The expected profit}

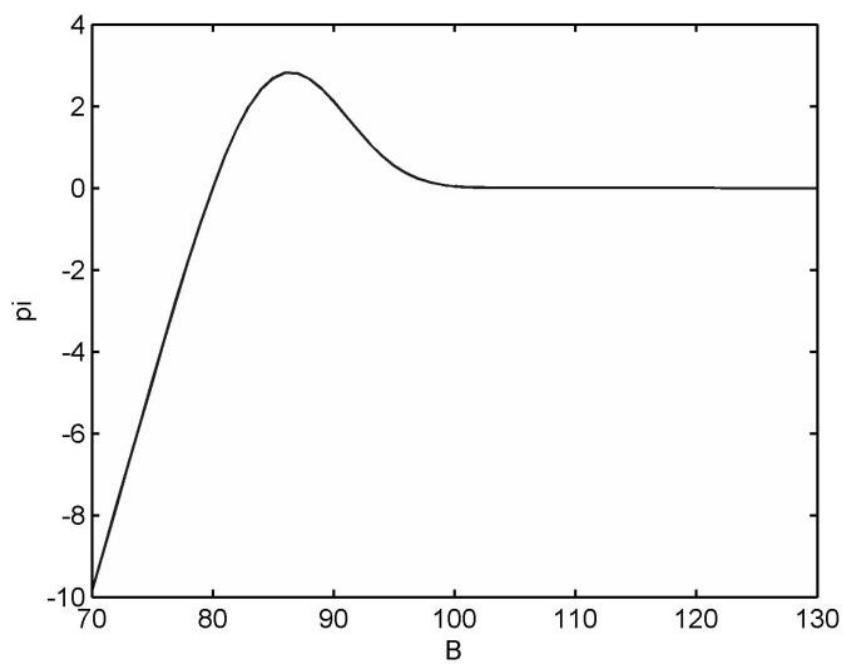

Source: Authorial computation using Matlab software, based on formula (3) for $C_{l}=80$, $n=10, B \sim N(100,102)$. 
Firm 1 (player) chooses its bid price to maximize the value of the expected profit.

$$
\max \Pi_{e}\left(B_{1}\right)=\left(B_{1}-C_{1}\right) \cdot\left[1-F\left(B_{1}\right)\right]^{n-1}
$$

After the maximization (relative to $B_{1}$ ), we get the following first order condition.

$$
1-F\left(B_{1}^{*}\right)=(n-1)\left(B_{1}^{*}-C_{1}\right) \cdot F^{\prime}
$$

In case of uniform distribution of bid prices on the interval $<\alpha ; \beta>$, i.e. $B \sim R(\alpha ; \beta)$, with the distribution function in the form $F(x)=\frac{x-\alpha}{\beta-\alpha}$, the bid price $B_{1}^{*}$ that maximizes the expected profit has the following form.

$$
B_{1}^{*}=\frac{\beta+C_{1}(n-1)}{n}
$$

The effect of expected number of bidders and the costs associated with the public contracts on bid price may be illustrated on the example of uniform distribution. The function of price (6) rises with the increase of costs $C_{l}$, which means that firms with lower costs should be under the same conditions offering a lower bid price. This function is also declining in $n$, while condition $C_{l}<\beta$ holds (can be reasonably expected ${ }^{5}$ ) and, therefore, more expected bidders are reflected in the reduction of the bid prices.

Instead of a uniform distribution companies may assume e.g. a normal distribution of bid prices $B \sim\left(\mu_{b} ; \sigma_{b}^{2}\right)$ with known mean $\mu_{b}$ and variance $\sigma_{b}^{2}$. The distribution function has in that case following form.

$$
F(x)=\int_{-\infty}^{x} \frac{1}{\sigma \sqrt{2 \pi}} e^{-\frac{(t-\mu)^{2}}{2 \sigma^{2}}} d t
$$

This form of distribution function complicates further calculations; therefore, it may be appropriate in this case of searching for the bid price that maximizes expected profit to use a numerical solution ${ }^{6}$. As in the previous case, a relationship between the bid prices, at which the expected profit is maximized, and firm's costs or expected number of tenderers may be found.

5 It can be assumed that the firm's costs $\mathrm{C} 1$ are lower than the expected upper limit of prices $\beta$ (for uniform distribution).

6 E.g. the solver tool in MS Excel or relevant functions in Matlab or other mathematical tools. 


\section{Fig. 3: Effect of costs}

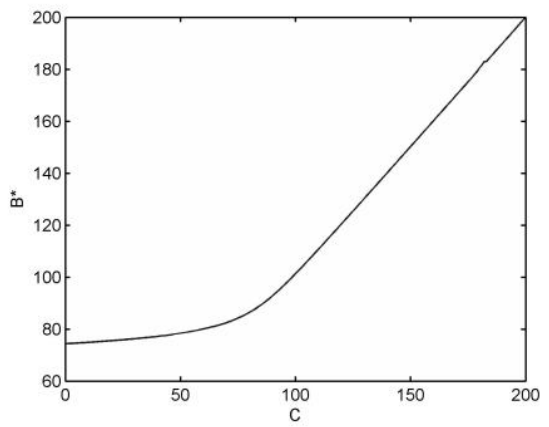

Fig. 4: Effect of number of bidders

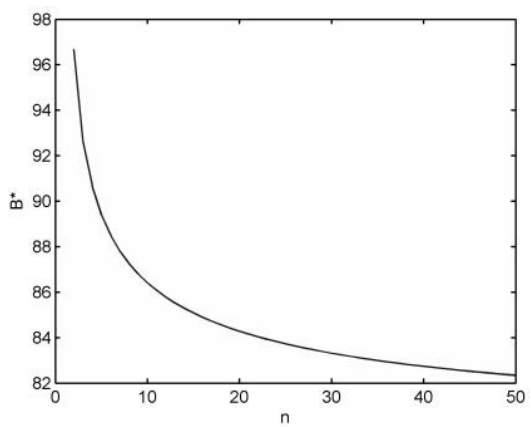

Source: Authorial computation using Matlab software.

The figures (3) and (4) show (for specific values ${ }^{7}$ ) an obvious positive correlation between the price and costs related to the contract, and a negative correlation between the bid price and expected number of firms to submit a tender.

The number of firms that submit a tender appears in the model as an exogenous variable which value is fixed in advance. Number of offers may, however, be determined within the model (i.e. endogenously) and this approach is illustrated below.

Suppose that in a given market exist $N$ companies that would be able to perform the public contract and meet the requirements given by the contracting authority. Further assume that the submission of the offer is connected with transaction costs $T$. These may be particularly the costs associated with preparing the tender, submitting required documents to prove the qualification, acquiring and studying of project documentation or costs of security deposit.

The value of transaction costs associated with preparing the tenders was empirically investigated e.g. in the survey conducted in 2012 (Pavel, 2013, pp. 5457). This value of induced transaction costs (including costs of searching for information on public procurement) reached in average 1,6\% of tendered price.

Every firm decides altogether with the derivation of bid price, at which the expected profit is maximized, whether to submit the tender. The firm, therefore, compares the expected profit that could be achieved (its maximum value) and the amount of transaction costs. If the expected profit without transaction costs is positive, the firm submits the tender, if this difference is negative (total expected loss), the firm does not submit the tender and so does not bear these transaction costs.

If $\Pi_{e}-T>0$, the firm submits the tender.

$7 n=10, \mu=100, \sigma=10$ for figure $3 ; C=80, \mu=100, \sigma=10$ for fig. 4 . 
All $N$ firms in the market do not need to participate in the award procedure, only $n$ players may submit the tender. Nevertheless, it is a question, whether the companies deciding on the bid price calculate rather estimated number of bids or number of the entities in the market (all potential competitors).

\section{Empirical verification of the conclusions of the model}

The conclusion of the model with multiple companies regarding the positive impact of the costs on bid price seems to be clear and intuitive, and is thus not necessary to be discussed, because it can be assumed that firms with higher costs will offer the performance with higher prices (on average). This fact would also be problematic to verify empirically, because data on costs of individual firms are unavailable in practice and cost calculations related to the specific contract would also be highly problematic and ambiguous.

On the other hand, the conclusion above regarding the negative impact of the number of tenderers to bid price in public procurement has been studied empirically on data in several cases. These empirical studies are therefore discussed in this chapter.

From the Czech environment, the research conducted transportation infrastructure projects may be mentioned (Pavel, 2010), which shows that the additional tenderer causes the contract price decline by average of $3,27 \%$ of predicted price.

Pavel (2013) performed another regression analysis of competitive effect (the effect of the number of tenderers on bid price) on data of public contracts awarded by organizations of central state administration. The influence of number of tenders on bid price has been shown for works, services and supply contracts (price decrease of approximately 3,2 \% for work, 4,6\% for services and 2,7 \% for service caused by additional tenderer). This effect, however, fades with an increasing number of tenders (because of the statistical significance of the square of the number of tenders). The study also suggests that use of open procedure has an impact, as it leads to a relatively high decline of price compared with other types of procurement procedure.

Of foreign studies, we can mention e.g. Li and Zheng (2009), who in the model analysed a negative relationship between the number of bids and the price (competitive effect) and also examined an effect that is related to the cost of entry into the market and has the opposite direction (entry effect). Empirical research on data from the auctioning of food purchased by US Department of Agriculture shows decline of the lowest bid of 4,2 to $8,3 \%$ depending on commodity between auctions with one and two participants; the effect is weaker with additional participants (MacDonald, Handy, Plato, 2002).

Onur, Ozcan and Tas (2012) report in the study of data on public contracts awarded in Turkey in 2004-2006 that presence of another tenderer causes the contract price decline by about $3,9 \%$ relatively to estimated value of public 
contract. The authors also highlight that the opening of public procurement to foreign competition leads to decline the price of approximately $11 \%$. GómezLobo and Szymanski (2001) found in the study on the cost of waste collection in the UK a significant impact of competition, as the presence of two participants led to a reduction in service costs by 12 to 13 per cent compared with a single bidder. Iimi (2006) examined auctions related to Japanese development assistance programs and based on data concludes that increasing the number of bidders by 1 $\%$ leads to a reduction of equilibrium bid price of around $0,2 \%$ (elasticity is equal to 0,2 ). Competitive effect leading to a decline in bid prices depending on the number of tenders is confirmed by data from auction for infrastructure development in developing countries (Estache, limi, 2008).

Regarding the factors influencing the number of submitted tenders, Pavel (2010) examined this topic using the regression model and found that the size of a public contract does not affect the number of submitted offers. The choice of restricted procedure, however, leads to a reduction in the number of submitted tenders of 2,6 in average; participation of an association of in award procedure reduces the number of tenders by 1,2 ; and a higher weight of bid price in the evaluation criterion of economic advantage is reflected in a higher number of submitted tenders. The article also explained relation between number of tenders and price that large construction companies participating in procurement adjust their bids according to the expected number of submitted tenders. When expecting higher number of tenderers they lower their bid prices to increase the probability of winning. This behaviour should be documented by the fact that five largest construction companies win on average $54 \%$ of contracts.

The conclusion regarding construction contracts suggests that expected number of submitted tenders has higher impact on bid price than total number of firms in the market (potential competition). In reality, moreover, the companies does not need to know the number of firms in the market that are able to perform the particular contract, for instance because of possible entry of new firms to the market or involvement of foreign suppliers within the European single market. In contrast, the number of tenderers in similar award procedures can be quite easily monitored. The average number of tenders received in public contracts recorded in the Journal of public procurement (Věstník veřejných zakázek) in 2013 was 4.24 according to the Ministry of Regional Development (2014), (see table 4). In case of contracting entities in the utility sector the average was less than 3 tenders; more tenders were received by contracting entities in works contracts (an average of almost 6 tenders). 
Schmidt, M.: Price Determination in Public Procurement: A Game Theory Approach.

Tab. 4: Number of submitted tenders

\begin{tabular}{cccc}
\hline Year & $\begin{array}{c}\text { Number of contracts } \\
\text { awarded }\end{array}$ & $\begin{array}{c}\text { Total number of } \\
\text { submitted tenders }\end{array}$ & $\begin{array}{c}\text { Average number of } \\
\text { submitted tenders }\end{array}$ \\
\hline 2008 & 8701 & 39393 & 3.71 \\
2009 & 10786 & 72011 & 4.03 \\
2010 & 9663 & 73853 & 4.18 \\
2011 & 8763 & 65247 & 4.60 \\
2012 & 10845 & 79813 & 4.16 \\
2013 & 16330 & 111167 & 4.24 \\
\hline
\end{tabular}

Source: MMR, 2014.

The presented model based on game theory and presented empirical research indicates a clear conclusion that the higher number of tenders decreases the bid price; this effect diminishes with growth of submitted tenders. This relation may be caused by expectations about number of bidders based on previous observations. More tenderers also mean higher probability of occurrence a tenderer with a different cost structure, i.e. with a lower price. The number of suitable supplier is determined by market structure, however, the contracting authority may to some extent affect how many of these suppliers will participate the award procedure. An approach aiming to increase the number of tenders therefore seems to be reasonable, especially in procurement in which low number of participants can be expected. Such an approach may be, for example simplifying the requirements for qualification, selection of suitable type of award procedures, simplifying the administration related to the submission of offer or other reduction of transaction costs on the bidders ${ }^{8}$.

\section{Conclusion}

Determination of the bid price in public procurement is an important decision that defines whether a tenderer wins the contract or not. The process of price determination does not need to respect only associated costs but the tenderer may act strategically and calculate with expected prices of other firms. The game theory is useful for analysis of similar decision situations and that was the goal of this article.

The article illustrated that decisions of tenderers can be analysed using the game theory approach. It was shown that firms might calculate expected profit when selecting their bid price. The expected profit is determined by the product of the profit gained in the performance of public contract, and the likelihood that the firm wins the contact at the price. If we limit the number of players and simplify their decisions on several levels of price, we can examine the mechanism of mutual influence through matrix games. It was shown in the article that two firms

8 e.g. the documents proving the qualification are submitted only by selected tenderer in the case of simplified below-threshold procedure, which reduces transaction costs for companies that are not selected. 
deciding on two levels of price might be described by prisoner's dilemma or stag hunt game depending on parameter value. When releasing these assumptions it is a similar issue, which is solved by the game theory in case of auctions. After the expected profit function is maximized, it is possible to trace dependence among the bid price of the company, its costs and number of tenderers.

It was shown that higher costs mean higher bid price, while more anticipated bidders cause the decline of the price. The actual functional dependence was not tested due to a problem of unavailable data on the cost of firm related to public procurement. The negative relationship between the bid price and number of bidders was at least confronted with literature. The empirical studies confirmed this relation and concluded that presence of another tenderer causes the contract price decline by about $4 \%$. The studies also confirmed that the influence of the expected number of submitted bids on tender price weakens with an increasing number of tenderers (parameter of influence of additional bidder may be insignificant from certain level).

The most significant benefit of price reduction can therefore be achieved for type of contracts involving smaller number of firms. A convenient way to increase the number of submitted tenders (except reduction of excessive qualification requirements) seems to be reducing transaction costs that are borne by the companies in connection with the submission of the tender.

A single parameter of contract - the price was only observed in the article; however, criterion of quality is also essential in some contracts. It should be possible to expand the presented models this way.

\section{References}

Bajari, P., 2001. Comparing Competition and Collusion: A Numerical Approach, Economic Theory 18, 187-205.

De Silva, D. G., Kosmopoulou, G., Lamarche, C., 2008. The Effect of Information on the Bidding and Survival of Entrants in Procurement Auctions, Journal of Public Economics 93, 56-72.

Dlouhý, M., Fiala, P., 2009. Úvod do teorie her. Oeconomica, Praha.

Eriksson, P. E., 2007. Efficient governance of construction projects through cooperative procurement procedures, Luleå University of Technology. Available from: <http://epubl.ltu.se/1402-1544/2007/27/LTU-DT-0727-SE.pdf〉. [17 August 2014].

Estache, A., Iimi, A., 2008. Procurement Efficiency for Infrastructure Development and Financial Needs Reassessed, The World Bank. Available from: <http://elibrary.worldbank.org/doi/pdf/10.1596/1813-9450-4662>. [17 August 2014]. 
Schmidt, M.: Price Determination in Public Procurement: A Game Theory Approach.

Gilley, O. W., Karels G. V., 1981. The Competitive Effect in Bonus Bidding: New Evidence, The Bell Journal of Economics 12, 637-648.

Glumaca, B., Hana, Q., Schaefera, W., Krabben, E., 2015. Negotiation issues in forming public-private partnerships for brownfield redevelopment: Applying a game theoretical experiment, Land Use Policy 47, 66-77.

Gómez-Lobo, A., Szymanski, S., 2001. A Law of Large Numbers: Bidding and Compulsory Competitive Tendering for Refuse Collection Contracts, Review of Industrial Organization 18, 105-113.

Ho, S. P., 2007. Government Policy on PPP Financial Issues: Bid Compensation and Financial Renegotiation, Working Paper. Available from: <https://gpc.stanford.edu/sites/default/files/wp029_0.pdf>. [17 August 2014].

Iimi, A., 2006. Auction Reforms for Effective Official Development Assistance, Review of Industrial Organization 28, 109-128.

Li, T., Zheng, X., 2009. Entry and Competition Effects in First-Price Auctions: Theory and Evidence from Procurement Auctions, The Review of Economic Studies 76, 1397-1429.

MacDonald, J. M., Handy, Ch. R., Plato G. E., 2002. Competition and Prices in USDA Commodity Procurement, Southern Economic Journal 69, 128-143.

Medda, F., 2007. A game theory approach for the allocation of risks in transport public private partnerships, International Journal of Project Management 25, 213218.

Ministerstvo pro místní rozvoj, 2014. Výroční zpráva o stavu veřejných zakázek v České republice za rok 2013. Praha. Available from: <http://www.portalvz.cz/getmedia/8965ea38-8a96-490b-ad0f-ce4e1c0a32c9/Vyrocni-zprava-o-stavuverejnych-zakazek-za-rok-2013.pdf>.[9 August 2014].

Onur, I., Ozcan, R., Tas, B. K. O., 2012. Public Procurement Auctions and Competition in Turkey, Review of Industrial Organization 40, 207-223.

Osborne, M. J., 2004. An introduction to game theory. New York, N.Y.: Oxford University Press 17, 533.

Pavel, J., 2010. Analýza vlivu míry konkurence na cenu rozsáhlých staveb dopravní infrastruktury, Politická ekonomie 3, 343-356.

Pavel, J., 2013. Veřejné zakázky a efektivnost. Ekopress, Praha.

Porter, R. H., Zona, J. D., 1993. Detection of Bid Rigging in Procurement Auctions, The Journal of Political Economy 101, 518-538. 